\title{
Brief Analysis on diversified teaching models of vocal music classroom teaching
}

\author{
Jindong Zhang \\ Hubei Normal University, Huangshi Hubei, 435002, China
}

Keywords: Vocal music classroom, Teaching practice, Diversity, Teaching model.

\begin{abstract}
Implementation of vocal music course has great impact for college students to lay good foundation of vocal music theories and master the vocal music skills, and has attracted great attention from college faculty and students in music major. But with the implementation of higher education enrollment expansion policies, and the gradual increase of staff-student ratio in college music major, there exist some difference in student professional skills so that the teaching efficiency of vocal course in large class instruction is not satisfactory. How to improve the teaching efficiency in vocal music classroom teaching has become a problem urgently to be solved. This article starts from diversified teaching models to analyze the application of vocal music classroom teaching so as to provide some support for improving vocal music classroom teaching quality.
\end{abstract}

\section{Introduction}

With social development and progress, Chinese educational career has developed greatly. The country's great attention to educational career has hugely promoted the teaching reform in each major of universities at all levels with the purpose of promoting students' comprehensive development through all-sided education and instruction. With the popularization of higher education, colleges have gradually proposed enrollment expansion policies and the amount of students in music major has increased sharply, which brought about impact on relevant course teaching especially on vocal music course integrating theory and skill teaching as the increase of student quantity has worsened the ratio imbalance between teachers and students. Lack of scientific teaching model, vocal music classroom teaching result is not satisfactory and the effect of cultivating students' comprehensive vocal quality is poor, which has severely limited the sustainable and steady development of vocal music teaching. Thus, in the new age, it is necessary to combine the demand of vocal music course teaching to explore more scientific education model and provide comprehensive instruction and guidance for students, so as to substantially cultivate students' vocal music comprehensive quality while improving vocal music teaching quality.

\section{Major problems existing in current college vocal music classroom teaching}

\section{Lack of effective cooperation between teachers}

In college music teaching practice, there exist close relations between each related subjects and there are some similarities in teaching contents and methods for different teachers in front of the same group of students. But in fact, in current music course teaching, teachers for different course usually lack effective communication and cooperation and they often apply isolated teaching methods and complete their own teaching assignments on their own. The existence of this teaching model usually make students unable to effective integrate knowledge points of each subject in professional learning 
process so that their comprehensive learning effect is poor and the cultivation of students' vocal music accomplishment is not satisfactory.

\section{Unreasonable ratio between theory and practical teaching in the teaching process}

Only through organic integration between theory and practice in any subject's teaching activities can gradually improve teaching efficiency and promote students' knowledge application ability to be well cultivated and improve their comprehensive quality. Particularly for vocal music course, as a strong skill-oriented subject, teachers must instruct some theoretical knowledge and also pay attention to the cultivation of students' vocal music skills so that students can combine theories with practice and achieve good learning results. But in actual teaching, some teachers only pay attention to theories or skill teaching, which seriously impacts teaching efficiency and harms the cultivation of students' vocal music accomplishments.

\section{Traditional and single teaching pattern}

In the new age, influenced by advanced educational ideologies, Chinese vocal music teachers have started explore brand new teaching pattern but in the whole most teachers are still following traditional teaching models so that student's subjectivity cannot be highlighted accordingly, the classroom is bored and tedium, which has brought about bad influence on students' learning interest and efficiency and even dispelled students' learning activity, and seriously limited the cultivation of students' vocal music accomplishment.

\section{Insufficient teaching target}

The concept of new curriculum reform proposed that teacher should actively transform their own teaching concepts and provide targeted education and instruction for students, highlight students' subjectivity. But in the actual teaching process of vocal music course, due to the unreasonable student-teacher ratio, teachers usually cannot provide targeted education and instruction based on students' practical condition so that their subjectivity is limited. Meanwhile, some vocal music teachers are too anxious for success in the teaching process and they are over enthusiastic about teaching and impose the learning ideas that they think reasonable to students, which make students' individualized study cannot be strengthened and the overall teaching effect is not satisfactory.

\section{Necessity of integrating diversified teaching models into vocal music teaching classroom}

Application of diversified teaching model can produce some positive impact on vocal music classroom teaching and promote the teaching effect and cultivation of students' vocal music accomplishment. Details are shown in following aspects:

\section{Application of diversified teaching models can help improve students' artistic accomplishment}

Vocal music course teaching as the course of music art major, also pays attention to the cultivation of students' artistic accomplishment during the teaching practice for the purpose of promoting students' comprehensive development through reasonable educational teaching. But traditional teaching models have some disadvantages, which has limited the cultivation of students' vocal music accomplishment and brought about negative impact on strengthening students' artistic accomplishment. Application of diversified teaching model into vocal music teaching practice can help students to combine vocal music theories learning with vocal music skill training and promote the reinforcement of their own artistic accomplishment. Meanwhile, teachers set up case explanation and music appreciation courses for students to help students improve their own music and art appreciation ability and artistic accomplishment. While learning professional vocal music knowledge and bring about positive influence on students' f future development. 


\section{Reasonable application of diversified teaching models can enrich students' practical activities}

Under the influence of new curriculum reform concept, many subject in colleges and universities focus on theory-practice combination for the purpose of promoting students' comprehensive quality improvement through integral education and instruction. But in college vocal music course teaching practice, traditional teaching methods are single, theory-practice ratio is not reasonable, and the teaching practice is insufficient, which has limited students' comprehensive development. With the support of diversified teaching models, teachers can try group learning and interactive teaching and other methods when carrying out vocal music teaching, avoid the defects of traditional teaching models so as to truly combine the theoretical teaching and practical training, provide platform for students to participate social practice, and promote students gradually reinforce their own practical ability under the guidance of learning theoretical knowledge of vocal music, and provide guarantee for cultivating students' comprehensive quality and development.

\section{Increase students' learning ability with the support of diversified teaching models}

In the new age, social development has proposed new requirement for college talent cultivation work, and traditional professional talents cannot satisfy the social demand any longer, and enterprises pay more attention to the introduction of comprehensive talents. Based on this, college should focus on students' professional cultivation but also stress the cultivation of students' learning ability so that they can continuously absorb related knowledge after graduation and improve comprehensive quality and provide guarantee for students' future employment ${ }^{[1]}$. Application of diversified teaching model can satisfy the demand of college talent cultivation. With the support of diversified teaching model, teachers can provide targeted education and instruction based on students' practical condition. In this way, students can improve their own professional quality under the teachers' targeted instruction but can also strengthen their own learning ability and improve their own comprehensive quality and adapt to job demand after graduation and obtain good career development. It is obvious that the application of diversified teaching model has positive impact on the cultivation of students' learning ability and their future development.

\section{Specific application of diversified teaching model in college vocal music classroom}

Based on problems existing in Chinese vocal music classroom teaching and advantages of applying diversified teaching model into college vocal music course teaching, college and universities should correctly realize the importance of exploring diversified teaching model and then try to apply diversified teaching model into teaching practice, and gradually improve the current teaching condition, and provide more professional education and instruction so that students' comprehensive vocal music quality can be cultivated well and provide solid guarantee for the students of vocal music major to have a better future development.

\section{Carry out group learning}

In college vocal music teaching, under the influence of enrollment different, different students have different knowledge basis and learning abilities. Therefore, to guarantee students' equally acceptance of fair educational instruction with the support of scientific educational guidance and achieve students' mutual progress, teachers can carry out group learning with the help of applying diversified teaching model, and combine students' practical condition, interest and hobbies, and learning degree to divide them into several learning groups, six to eight students in one group, and make sure students can take collaborative learning on the basis of receiving teachers' uniform guidance to truly realize the complementary advantages of vocal music teaching and improve teaching quality ${ }^{[2]}$. Meanwhile, teachers can master students' learning condition by combining students' performance in different groups so as to provide targeted education and tutorship for members in each group and make sure that students can acquire vocal music skill under the special guidance of teacher while mastering some vocal music theoretical knowledge to promote the reinforcement of their vocal music 
accomplishment. In this way, with the support of group cooperation and study, college vocal music teaching quality will be significantly improved and students' solidarity and cooperation ability can be well cultivated, which is with high application value, good for students' comprehensive development and the mutual development of all students.

\section{Carry out interactive teaching}

The proposal of new curriculum reform concept requires that teachers should pay attention to the student subjectivity in teaching practice and the design of each teaching activity and the allocation of teaching tasks should set students as the subject so as to fully mobilize students' subjective initiative and get them actively engaged into teaching activities and achieve good learning efficiency. For college vocal music classroom teaching, teachers can try to use interactive teaching method during the process and create good teaching atmosphere through teacher-student and student-student interaction to improve students' learning experience and teaching effect.

For example, when teacher are instructing the knowledge of "correct respiration and singing condition", some students may not have a correct singing mindset and make mistakes of breathing during singing which will influence the learning effect. At this moment, teachers can carry out interactive teaching and let students communicate and exchange, and share their experience of good singing mindset, promote students to learn other students' experience, and then to relax during the communication and grasp correct breathing skills gradually and gain a good singing attitude and improve learning result ${ }^{[3]}$. Meanwhile, teachers should strengthen the interaction with students and carry out individual instruction on problems existing students' learning process and set examples for them so that they can form a correct understanding of signing and find problems for timely correction and improve learning effect. In addition, based on the application of information technology, teachers can try to increase the after-class interaction, such as establish WeChat group and QQ group, for students to communication and exchange after classes, and provide platform for student-teacher interaction, and offer guarantee for improving vocal music teaching efficiency.

\section{Carry out multi-media education}

With the widely application of information technology in education field, multi-media is becoming an important teaching method bring about positive influence on improving overall teaching quality and students' comprehensive quality cultivation. During the college vocal music teaching, with the help of applying multi-media technology, teachers can combine theoretical interpretation and practical education so that students' vocal music skills can be cultivated well and lay solid foundation for cultivating students' vocal music accomplishment and improvement of comprehensive ability.

For example, when teaching the song "Kiss the Motherland", and strengthening students' throat stability, character vocalization, and singing expressive force, teachers can firstly apply multi-media equipment to show students the video of famous singers singing "Kiss the Motherland" and combine different parts of singing to analyze the singing skills used by singers and the expression of singing emotions. After students form a preliminary understanding of singing skill issues, teachers can organize students to take intensive training and carry out targeted guidance for students. At last, teachers can record their singing after training into videos and let them compare with famous singers after classes. In this, way, students can form profound understanding of the singing skill, and song's artistic expressive force during comparing with the famous singers' singing so as to find out their defects and make continuous adjustment and correction and improve learning efficiency ${ }^{[4]}$. In this way, with the help of applying multi-media equipment, teachers can complete theoretical knowledge interpretation through videos and audios with more pertinence, and help students combine theories with practice during leaning and form more systematic understanding of vocal music knowledge and truly improve their own vocal music accomplishment.

It can be seen that application of multi-media teaching model in college vocal music classroom teaching, pertinence, systematicness, interaction and openness of teaching can be significantly improved, which is good for the intensification of teaching quality and cultivation of students' comprehensive quality. 


\section{Conclusion}

To sum up, there still exist some problems in Chinese current college vocal music classroom teaching, which has brought about negative influence on students' professional development and cultivation of comprehensive quality, and resulted in poor overall teaching efficiency. Therefore, under the background of new curriculum reform, it is necessary to carry out comprehensive education and instruction, so as to promote students to improve their own vocal music quality and artistic accomplishment under teachers' guidance and provide solid guarantee for students' future development.

\section{Reference}

[1] Li Jiuyun. Brief analyais on diversified teaching model in vocal music classroom, Modern Music, 2015(34):25-26.

[2] Zhang Yuling. Innovative teaching model activate vocal music classroom, Education \& Teaching Forum Periodicals Agency, 2015(28):126-127.

[3] Gao Jinxiang. Application of diversified teaching model to improve vocal music teaching efficiency-discussion on effective strategies of vocal music teaching in secondary vocational schools, Course Education Research (New teacher teaching), 2013(36):297-297,288.

[4] Qin Dongchun. Brief analysis on vocal music diversified performance teaching in advanced normal university music classroom, New Education Era (Teacher version), 2015(28):34-34. 